\title{
The prevalence of cardiovascular risk factors and cardiovascular disease among primary care patients in Poland: results from the LIPIDOGRAM2015 study
}

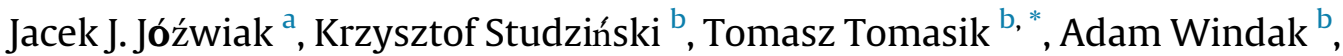 \\ Mirosław Mastej ${ }^{\mathrm{c}}$, Alberico L. Catapano ${ }^{\mathrm{d}}$, Kausik K. Ray ${ }^{\mathrm{e}}$, Dimitri P. Mikhailidis ${ }^{\mathrm{f}}$, \\ Peter P. Toth ${ }^{\mathrm{g}}{ }^{\mathrm{h}}$, George Howard ${ }^{\mathrm{i}}$, Gregory Y.H. Lip ${ }^{\mathrm{j}, \mathrm{k}}$, Maciej Tomaszewski ${ }^{\mathrm{l}}$, \\ Fadi J. Charchar ${ }^{\mathrm{m}}$, Naveed Sattar ${ }^{\mathrm{n}}$, Bryan Williams ${ }^{\circ}$, Thomas M. MacDonald ${ }^{\mathrm{p}}$, \\ Dariusz Nowak ${ }^{\mathrm{q}}$, Łukasz Skowron ${ }^{\mathrm{r}}$, Sławomir Kasperczyk ${ }^{\mathrm{s}}$, \\ Maciej Banach ${ }^{\mathrm{t}}$, on behalf of the LIPIDOGRAM2015 Investigators* \\ ${ }^{a}$ Department of Family Medicine and Public Health, Faculty of Medicine, University of Opole, Oleska 48, 45-052, Opole, Poland \\ ${ }^{\mathrm{b}}$ Department of Family Medicine, Jagiellonian University Medical College, Bochenska 4, 31-061, Krakow, Poland \\ ${ }^{c}$ Mastej Medical Center, Staszica 21, 38-200, Jasto, Poland \\ d Department of Pharmacological Sciences University of Milano and Multimedica IRCCS, Milano, Italy \\ e Imperial Centre for Cardiovascular Disease Prevention, Department of Primary Care and Public Health, Imperial College, Kensington, London, UK \\ ${ }^{\mathrm{f}}$ Department of Clinical Biochemistry, Royal Free Hospital, University College London, London, UK \\ g Cicarrone Center for the Prevention of Cardiovascular Disease, Johns Hopkins University School of Medicine, Baltimore, MD, USA \\ ${ }^{\mathrm{h}}$ CGH Medical Center, Sterling, IL, USA \\ ${ }^{i}$ Department of Biostatistics, School of Public Health of Alabama at Birmingham, AL, USA \\ ${ }^{\mathrm{j}}$ Liverpool Centre for Cardiovascular Science, University of Liverpool and Liverpool Heart \& Chest Hospital, Liverpool, UK \\ ${ }^{\mathrm{k}}$ Aalborg Thrombosis Research Unit, Department of Clinical Medicine, Aalborg University, Aalborg, Denmark \\ ${ }^{1}$ Division of Cardiovascular Sciences, Faculty of Biology, Medicine and Health, University of Manchester, UK \\ ${ }^{\mathrm{m}}$ School of Health and Life Sciences, Federation University Australia, Ballarat, Victoria, Australia \\ ${ }^{\mathrm{n}}$ Institute of Cardiovascular and Medical Science, University of Glasgow, Glasgow, G128TA, UK \\ ${ }^{\circ}$ NIHR University College London Biomedical Research Centre, University College London and University College London Hospitals NHS Foundation Trust, \\ London, UK \\ p MEMO Research, University of Dundee, Ninewells Hospital and Medical School, Dundee, DD1 9SY, UK \\ ${ }^{\mathrm{q}}$ Municipal Hospital, Mickiewicza 12, 42-200, Czestochowa, Poland \\ ${ }^{r}$ Department of Gastroenterology, Endocrinology and Internal Diseases, Military Institute of Medicine, Szaserow 128, 04-141, Warszawa, Poland \\ ${ }^{s}$ Department of Biochemistry, Faculty of Medical Sciences in Zabrze, Jordana 19 41-808 Zabrze, Medical University of Silesia, Katowice, Poland \\ ${ }^{\mathrm{t}}$ Department of Hypertension, Medical University of Lodz, Rzgowska 281/289, 93-338, Eodz, Poland
}

\section{Keywords:}

Cardiovascular disease

Cardiovascular risk factors

Hypertension

Hypercholesterolaemia

Diabetes mellitus

Obesity

Primary health care

Poland

\begin{abstract}
A B S T R A C T
Background and aim: To estimate the prevalence of cardiovascular (CV) disease and CV risk factors among Polish patients.

Methods: A nationwide cross-sectional study, LIPIDOGRAM2015, was carried out in Poland in the 4th quarter of 2015 and 1st and 2nd quarters of 2016; 438 primary care physicians enrolled 13,724 adult patients that sought medical care in primary health care practices.

Results: Nearly $19 \%$ of men and approximately $12 \%$ of women had cardiovascular disease (CVD). Over $60 \%$ of the recruited patients had hypertension (HTN), $>80 \%$ had dyslipidaemia and $<15 \%$ of patients were diagnosed with diabetes (DM). All of these disorders were more frequent in men. In $80 \%$ of patients the waist circumference exceed norm for the European population. Less than half of the patients were current smokers or had smoked in the past. Patients with CVD had significantly higher blood pressure and glucose levels but lower low density lipoprotein-cholesterol level.

Conclusions: The prevalence of CVD and CV risk factors among patients in Poland is high. CVD is more common in men than in women. The most common CV risk factors are excess waist circumference,
\end{abstract}

\footnotetext{
* Corresponding author. Department of Family Medicine, Jagiellonian University Medical College, Bochenska 4, 31-061, Krakow, Poland.

E-mail address: mmtomasi@cyf-kr.edu.pl (T. Tomasik).
} 
dyslipidaemia and HTN. Family physicians should conduct activities to prevent, diagnose early and treat CVD in the primary health care population.

() 2021 Elsevier B.V. This is an open access article under the CC BY-NC-ND license (http:// creativecommons.org/licenses/by-nc-nd/4.0/).

\section{Background}

Cardiovascular disease (CVD) is currently one of the leading cause of mortality in the European Union (EU), where it causes around 800,000 deaths in men and 1 million deaths in women annually [1]. In 2015, within the EU, almost 49 million people were living with CVD. A higher CVD mortality burden is found in Central and Eastern European (CEE) countries compared with Northern, Southern and Western European states. In Greece in 2015, the agestandardised prevalence rate of CVD per 100,000 in women and men was 4052 and 5,189, respectively. During the same year, these rates in Poland were 6709 and 8830 [2,3].

Well-known, modifiable cardiovascular (CV) risk factors include elevated blood pressure (BP), hypercholesterolaemia, diabetes mellitus, obesity, low activity levels, poor diet and smoking. The prevalence of these, as well as the prevalence of CVD itself, are more common in the CEE than in Western Europe. In Poland, as in other countries of the CEE region (e.g. Slovakia and the Czech Republic), the prevalence of $\mathrm{CV}$ risk factors (except smoking) is increasing continuously [2].

There are estimates on the prevalence of $\mathrm{CV}$ risk factors in Poland, conducted at the beginning of previous decade on small segments of the population that only partially include primary care patients (e.g. NATPOL 2011 [4,5], WOBASZ II (2013/14) [5,6]). However, there are no current estimates on the prevalence of CV risk factors among patients solely in the primary care setting. LIPIDOGRAM $[7,8]$ is a large cross-sectional study that was initiated in 2010, with a continuation of data collection in 2015 and 2016.

Improved control and reducing the prevalence of $\mathrm{CV}$ risk factors is one of the principal goals of primary care medicine. Effective primary care and preventative medicine can modify premature death, myocardial infarction (MI), ischemic stroke, and need for revascularization among patients at risk. Physicians providing primary health care identify and treat patients with CV risk factors and play prominent roles in implementing CVD prevention strategies within the communities they serve. According to the guidelines of the European Society of Cardiology (ESC), general practitioners (GPs) should provide CV risk factor evaluation, deliver intervention for high-risk patients, and educate patients. GPs should also detect CVD at an early stage, treat patients, and cooperate with other health professionals so as to optimize health care delivery $[9,10]$.

The preventable mortality rate in Poland decreased by about $10 \%$ between 2011 and 2016. However, it continues to be higher than in most EU Member States [11]. Knowledge of CV risk factor prevalence in the Polish population is necessary in order to implement a broad, effective strategy aimed at reducing mortality, morbidity, and disability resulting from CVD.

\section{Aim}

The aim of this study is to determine: (1) the prevalence of CV disease, and, (2) ascertain CV risk factor prevalence, including hypertension (HTN), impairments in glycemic control, and cholesterol fraction levels in men and women treated in primary care in Poland.

\section{Methodology}

\subsection{Design}

A nationwide cross-sectional study, LIPIDOGRAM2015, was carried out in Poland in the 4th quarter of 2015 and 1st and 2nd quarters of 2016.

\subsection{Setting}

A group of 700 physicians-investigators working in public or private Primary Health Care Practices were randomly selected by principal investigator from the Medical Data Management database using computer software. The database includes national representation of primary care doctors. The group of 700 physiciansinvestigators was selected in a manner proportional to the number of inhabitants in a given administrative region (so called voivodeship). It was assumed that each physician-investigator will include at least 30 patients remaining under his medical care in the LIPIDOGRAM 2015 study. Due to the statistical correctness of the results, the number of patients included in the survey in the smallest Polish voivodeship (Lubuskie voivodeship - $2.64 \%$ of the population of Poland), should not be lower than 550 people. A total of 438 physicians in 398 practices in 16 major administrative regions were recruited.

\subsection{Participants}

Between October 2015 and June 2016, a total of 438 primary care physicians actively enrolled 13,724 patients. Inclusion criteria were: (1) age above 18 years, (2) being under the care of the givenphysician-investigator, (3) soughing care for any medical reason in primary health care practices, (4) give voluntary written consent to participate in the study. The patient was excluded if he (1) was legally deprived of the ability to make decisions or (2) planned to change his place of residence. $262(37,4 \%)$ physicians refused to participate, the main reason reported was lack of time. Each physician-investigator consecutively recruited into this study at least 30 adults attending their primary care practices. Prior to data collection, each physician-investigator undertook individual training related to the study procedure and methodology as described in the LIPIDOGRAM2015 study design [12]. A flow-chart of patients remarking the number of eligible participants, the number of selected and excluded patients, is presented as Supplementary material 1.

\subsection{Measurements}

For each patient recruited for the study, a 28 item questionnaire was collected that gathered data on chronic diseases and their treatment, lifestyle (diet, physical activity, smoking status), and family history of CVD (altogether 24 questions). The questionnaire also recorded demographic data: age, sex, place of residence and level of education (altogether 4 questions). To prevent missing data only critical data elements were collected to minimize burden and focus on data routinely collected. The questionnaire was tested in a group of 10 primary care physicians who did not submit comments 
or noted difficulties in completing it. The content validity was checked by comparing the questionnaire with other similar tools used in Poland (the English translation of the questionnaire is presented in the LIPIDOGRAM2015 study design [12].

In all patients, anthropometric measurements were made (height, body weight, waist circumference and hip circumference). Height and weight measurements were carried out without heavy clothing and shoes. Waist circumference was measured over the unclothed abdomen at a level of the midpoint between the lower margin of the ribs and the anterior superior iliac crest spine. Hip circumference was measured at the level of the greater trochanters. On the same day, measurements of BP and fasting glucose and lipid profile were taken. Patients were fasting for at least $12 \mathrm{~h}$ prior to the blood sample collection.

The collected blood samples were transferred in cooled containers to the central laboratory (Silesian Analytical Laboratories in Katowice, Poland). Measurements of total cholesterol, triglycerides, high-density lipoprotein cholesterol (HDL-C) and low-density lipoprotein cholesterol (LDL-C) (both by direct immunological measurement) were made using the same methodology and the same SIEMENS ADVIA 1800 analyser and SIEMENS reagents, within $12 \mathrm{~h}$ of drawing. The reference intervals of laboratory parameters were based on ESC guidelines of 2011 [13]. Fasting glycaemia was measured using BIONIME glucometers and RIGHTEST strip tests, which indicated an acceptable accuracy and precision [14]. On the same day, office BP measurements were performed with standard sphygmomanometers according to 2013 ESC/ESH Guidelines for the management of arterial HTN [15].

\subsection{Definitions and classification}

HTN, DM and dyslipidaemia were defined in accordance with current guidelines (presented also in Supplementary material 2) $[13,16,17]$.

Patients were defined as with HTN when: (1) HTN was prior diagnosed; or (2) patient used at least one hypotensive medication; or (3) office SBP was $\geq 140 \mathrm{mmHg}$ and/or office DBP was $\geq 90 \mathrm{mmHg}$. Patients were defined as with dyslipidaemia when: (1) dyslipidaemia was prior diagnosed; or (2) patient used at least one lipid-lowering medication; or (3) LDL-C level was $\geq 115 \mathrm{mg} / \mathrm{dl}$ and/ or TG level was $\geq 150 \mathrm{mg} / \mathrm{dl}$. Patients were defined as with DM when: (1) DM was prior diagnosed; or (2) patient used at least one hypoglycaemic medication.

Present CVD was defined as CVD confirmed prior to the onset of the LIPIDOGRAM study by invasive or non-invasive testing, and incuded: coronary heart disease (previous angina with or without acute coronary syndrome), previous myocardial infarction, atrial fibrillation or ischemic stroke [13].

WHO classification of obesity, based on the Body Mass Index (BMI), was used [18]. Normal waist circumference $(<80 \mathrm{~cm}$ in women and $<94 \mathrm{~cm}$ in men) was established according to the International Diabetes Federation (IDF) recommendations [19]. Abdominal obesity was defined as the waist-hip ratio (WHR) $\geq 1$ for men, and WHR $\geq 0.85$ for women. Smokers were defined as patients who smoked at least one cigarette daily. Patients were defined as being treated for HTN, DM or dyslipidaemia when they use at least one hypotensive or hypoglycaemic or lipid-lowering medication, respectively.

\subsection{Statistical analysis}

Frequency rates are presented for variables measured on a nominal or ordinal scale. The categorical variables were compared between the patients with and without CVD using the Pearson's chi-square and continuous variables were compared using the
Student $t$-test or the U Mann-Whitney test as appropriate. Statistical significance was determined when $\mathrm{p}$ is $<0.05$ and $\mathrm{p}$ values were unadjusted for multiple comparisons. All statistical analyses were conducted using the STATISTICA programme, version 13.

\subsection{Ethical issue}

All individuals signed an informed consent to participate in the study and gave their permission to use anonymous questionnaire data, the results of their laboratory tests and secured biologic material for the purpose of statistical and scientific studies.The LIPIDOGRAM2015 study received a positive opinion from the Bioethical Commission of the District Medical Chamber in Częstochowa on December 02, 2015 (No K.B.CZ.-0018/2015) and conforms to the principles outlined in the Declaration of Helsinki.

\section{Results}

\subsection{Population characteristics}

The LIPIDOGRAM2015 study involved 13,724 patients (8690 women and 5034 men). The average age was 56.4 years (56.2 in men, 56.4 in women). Demographic characteristics of enrolled patients including the division into those with and without CVD are presented in Table 1.

CVD was present in 1965 (15.4\%) of patients and was more common in men (19\%) than in women (11.6\%). Coronary heart disease was present in 1787 (13\%) of patients (10.4\% of women and $17.4 \%$ of men). MI was present in $625(4,6 \%)$ patients $(2.2 \%$ of women and $8.6 \%$ of men), ischemic stroke in 268 (2\%) of patients (1.6\% of women and $2.5 \%$ of men) and hemorrhagic stroke in 31 ( $0.2 \%$ ) of patients $(0.2 \%$ of women and $0.3 \%$ of men).

Over $60 \%$ of participants had HTN (58.4\% of women and $69.6 \%$ of men). Mean office BP values in patients treated for HTN were 139/ $83 \mathrm{mmHg}$, in people not treated for HTN mean BP values were 126/ $78 \mathrm{mmHg}$. Details regarding office systolic and diastolic BP are presented in Table 2.

DM was present in $11.8 \%$ of women and $16.3 \%$ of men. Mean glucose values in patients treated for DM were $137 \mathrm{mg} / \mathrm{dl}$ and in non-treated subjects, $99 \mathrm{mg} / \mathrm{dl}$ (Table 2).

Dyslipidaemia was present in $82.4 \%$ of women and $88.7 \%$ of men. In people treated for this condition, mean total cholesterol values were $192 \mathrm{mg} / \mathrm{dl}$ and mean LDL cholesterol values were $118 \mathrm{mg} / \mathrm{dl}$. In patients without treatment, mean total cholesterol values were $208 \mathrm{mg} / \mathrm{dl}$ and mean LDL cholesterol values were $134 \mathrm{mg} / \mathrm{dl}$ (Table 3).

In the study population during the relevant period, less than $17 \%$ of patients smoked cigarettes but almost $1 / 3$ reported that they had smoked in the past. Underweight was found in less than $1 \%$ of patients, and $25 \%$ of respondents had normal body weight. Overweight and obesity were present in almost $75 \%$ of participants (overweight in $39.5 \%$, first-degree obesity in $24.7 \%$, a second-degree in $7.6 \%$, and third-degree in $2.5 \%$ ). Waist circumference exceeding the norm was found in almost $80 \%$ of patients. Abdominal obesity was found in almost $45 \%$ of the subjects. The prevalence of CVD risk factors is shown in Fig. 1.

\subsection{The prevalence of CV risk factors in patients with CVD and without CVD}

In patients without CVD, HTN occurred in $58.2 \%$. In the subpopulation of patients with CVD, HTN was present in $88.5 \%$ (Fig. 1a). Mean BP values, as well as the differences in groups with and without CVD, are presented in Table 2.

DM was found in $10.6 \%$ of patients without CVD. Among patients 
Table 1

Demographic characteristics of patients with CVD and without CVD in the LIPIDOGRAM2015 study.

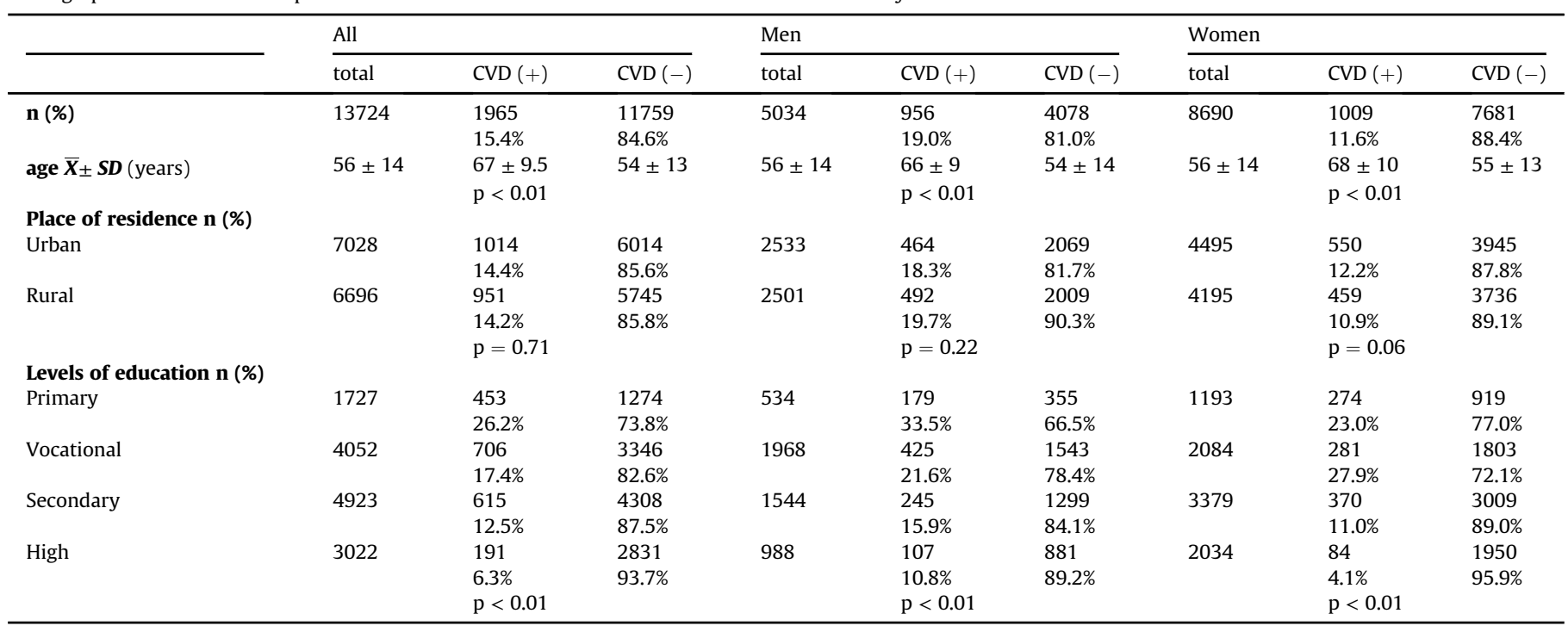

CVD - cardiovascular disease, SD - standard deviation.

Table 2

Level of BP and glucose in patients with CVD and without CVD in the LIPIDOGRAM2015 study.

\begin{tabular}{|c|c|c|c|c|c|c|c|c|c|}
\hline & All & Men & Women & & & & & & \\
\hline & total & $\operatorname{CVD}(+)$ & $\operatorname{CVD}(-)$ & Total & $\operatorname{CVD}(+)$ & $\operatorname{CVD}(-)$ & total & $\operatorname{CVD}(+)$ & $\operatorname{CVD}(-)$ \\
\hline $\begin{array}{l}\text { Total (n) } \\
\text { SBP }\end{array}$ & 13724 & 1965 & 11759 & 5034 & 956 & 4078 & 8690 & 1009 & 7681 \\
\hline$\overline{\boldsymbol{X}}_{ \pm} \boldsymbol{S D}(\mathrm{mmHg})$ & $132 \pm 18$ & $\begin{array}{l}137 \pm 19 \\
p<0.01\end{array}$ & $131 \pm 18$ & $\begin{array}{l}135 \pm 18 \\
\mathrm{p}<0.01\end{array}$ & $137 \pm 19$ & $\begin{array}{l}135 \pm 17 \\
p<0.01\end{array}$ & $130 \pm 19$ & $138 \pm 19$ & $129 \pm 18$ \\
\hline DBP & & & & & & & & & \\
\hline$\overline{\boldsymbol{X}}_{ \pm} \boldsymbol{S} \boldsymbol{D}(\mathrm{mmHg})$ & $80 \pm 11$ & $\begin{array}{l}81 \pm 11 \\
p<0.01\end{array}$ & $80 \pm 11$ & $\begin{array}{l}83 \pm 11 \\
p<0.01\end{array}$ & $82 \pm 11$ & $\begin{array}{l}83 \pm 10 \\
p<0.01\end{array}$ & $79 \pm 10$ & $81 \pm 11$ & $79 \pm 10$ \\
\hline $\begin{array}{l}\text { Treated for HTN (n) } \\
\text { SBP }\end{array}$ & 6515 & 1592 & 4923 & 2516 & 768 & 1748 & 3999 & 824 & 3175 \\
\hline $\begin{array}{l}\overline{\boldsymbol{X}}_{ \pm} \boldsymbol{S D}(\mathrm{mmHg}) \\
\text { DBP }\end{array}$ & $139 \pm 18$ & $\begin{array}{l}140 \pm 19 \\
p=0.04\end{array}$ & $139 \pm 18$ & $\begin{array}{l}140 \pm 18 \\
\mathrm{p}=0.11\end{array}$ & $139 \pm 19$ & $\begin{array}{l}141 \pm 18 \\
p<0.01\end{array}$ & $138 \pm 18$ & $140 \pm 19$ & $138 \pm 18$ \\
\hline$\overline{\boldsymbol{X}}_{ \pm} \boldsymbol{S} \boldsymbol{D}(\mathrm{mmHg})$ & $83 \pm 11$ & $\begin{array}{l}82 \pm 11 \\
p=0.01\end{array}$ & $83 \pm 11$ & $\begin{array}{l}84 \pm 11 \\
p=0.00\end{array}$ & $83 \pm 11$ & $\begin{array}{l}85 \pm 11 \\
p=0.20\end{array}$ & $82 \pm 10$ & $81 \pm 11$ & $82 \pm 10$ \\
\hline $\begin{array}{l}\text { Non-treated for HTN (n) } \\
\text { SBP }\end{array}$ & 7209 & 373 & 6836 & 2518 & 188 & 2330 & 4691 & 185 & 4506 \\
\hline$\overline{\boldsymbol{X}}_{ \pm} \boldsymbol{S D}(\mathrm{mmHg})$ & $126 \pm 16$ & $\begin{array}{l}129 \pm 17 \\
p<0.01\end{array}$ & $126 \pm 16$ & $\begin{array}{l}131 \pm 16 \\
p=0.47\end{array}$ & $130 \pm 18$ & $\begin{array}{l}131 \pm 16 \\
\mathrm{p}<0.01\end{array}$ & $124 \pm 16$ & $129 \pm 17$ & $123 \pm 16$ \\
\hline DBP & & & & & & & & & \\
\hline$\overline{\boldsymbol{X}}_{ \pm} \boldsymbol{S D}(\mathrm{mmHg})$ & $78 \pm 10$ & $\begin{array}{l}78 \pm 10 \\
p=0.98\end{array}$ & $78 \pm 10$ & $\begin{array}{l}81 \pm 10 \\
p<0.01\end{array}$ & $79 \pm 11$ & $\begin{array}{l}81 \pm 10 \\
p=0.19\end{array}$ & $77 \pm 10$ & $78 \pm 10$ & $77 \pm 10$ \\
\hline glycaemia $\bar{X}_{ \pm} S \boldsymbol{D}(\mathrm{mg} / \mathrm{dl})$ & $103 \pm 25$ & $\begin{array}{l}113 \pm 32 \\
\mathrm{p}<0.01\end{array}$ & $102 \pm 23$ & $\begin{array}{l}106 \pm 27 \\
\mathrm{p}<0.01\end{array}$ & $113 \pm 32$ & $\begin{array}{l}104 \pm 26 \\
\mathrm{p}<0.01\end{array}$ & $102 \pm 23$ & $112 \pm 32$ & $101 \pm 22$ \\
\hline Treated for DM (n) & 1728 & 570 & 1158 & 770 & 290 & 480 & 958 & 280 & 678 \\
\hline glycaemia $\bar{X}_{ \pm} S \boldsymbol{D}(\mathrm{mg} / \mathrm{dl})$ & $137 \pm 42$ & $\begin{array}{l}138 \pm 42 \\
p=0.54\end{array}$ & $137 \pm 42$ & $\begin{array}{l}139 \pm 42 \\
p=0.91\end{array}$ & $139 \pm 40$ & $\begin{array}{l}139 \pm 44 \\
p=0.91\end{array}$ & $136 \pm 42$ & $137 \pm 43$ & $135 \pm 41$ \\
\hline $\begin{array}{l}\text { Non-treated for DM (n) } \\
\text { glycaemia } \bar{X}_{ \pm} S D(\mathrm{mg} / \mathrm{dl})\end{array}$ & $\begin{array}{l}11996 \\
99 \pm 16\end{array}$ & $\begin{array}{l}1395 \\
102 \pm 19 \\
p<0.01\end{array}$ & $\begin{array}{l}10601 \\
98 \pm 16\end{array}$ & $\begin{array}{l}4264 \\
100 \pm 18 \\
p<0.01\end{array}$ & $\begin{array}{l}666 \\
102 \pm 19\end{array}$ & $\begin{array}{l}3598 \\
99 \pm 17 \\
p<0.01\end{array}$ & $\begin{array}{l}7732 \\
98 \pm 15\end{array}$ & $\begin{array}{l}7003 \\
97 \pm 15\end{array}$ & $\begin{array}{l}729 \\
102 \pm 19\end{array}$ \\
\hline
\end{tabular}

CVD - cardiovascular disease, DBP - diastolic blood pressure, SBP - systolic blood pressure, HTN - hypertension, DM - diabetes, SD - standard deviation.

with CVD, previously diagnosed DM was present in 30.7\% (Fig. 1a). Mean values of glycaemia and statistical significance of differences in the groups with and without CVD are presented in Table 2.

Dyslipidaemia was detected in $83.7 \%$ of people without CVD. Among patients with CVD, 90.8\% had dyslipidaemia (Fig. 1a). Mean values of cholesterol fraction, as well as the statistical significance of differences in groups without and with CVD, are presented in Table 3.
In patients without CVD, overweight was found in $39.9 \%$ and obesity in $32.8 \%$. Excess waist circumference $(\geq 80 \mathrm{~cm}$ in women and $\geq 94 \mathrm{~cm}$ in men) was detected in $77.4 \%$. Abdominal obesity (WHR $\geq 1$ for men and $\geq 0.85$ for women) was found in $43.1 \%$ (Fig. 1b).

In patients with diagnosed CVD, overweight was present in $36.6 \%$ and obesity in $47.3 \%$. Excess waist circumference $(\geq 80 \mathrm{~cm}$ in women and $\geq 94 \mathrm{~cm}$ in men) was detected in $88.9 \%$. Abdominal 
Table 3

Lipids profile in patients with CVD and without CVD in the LIPIDOGRAM2015 study.

\begin{tabular}{|c|c|c|c|c|c|c|c|c|c|}
\hline & \multicolumn{3}{|l|}{ All } & \multicolumn{3}{|l|}{ Men } & \multicolumn{3}{|l|}{ Women } \\
\hline & total & $\operatorname{CVD}(+)$ & $\operatorname{CVD}(-)$ & total & $\operatorname{CVD}(+)$ & $\operatorname{CVD}(-)$ & total & $\operatorname{CVD}(+)$ & $\operatorname{CVD}(-)$ \\
\hline Total (n) & 13724 & 1965 & 11759 & 5034 & 956 & 4078 & 8690 & 1009 & 7681 \\
\hline $\mathbf{T C} \bar{X}_{ \pm} \mathbf{S D}(\mathrm{mg} / \mathrm{dl})$ & $202 \pm 44$ & $\begin{array}{l}184 \pm 45 \\
p<0.01\end{array}$ & $206 \pm 43$ & $198 \pm 45$ & $\begin{array}{l}175 \pm 41 \\
p<0.01\end{array}$ & $203 \pm 44$ & $205 \pm 44$ & $\begin{array}{l}192 \pm 47 \\
p<0.01\end{array}$ & $207 \pm 43$ \\
\hline HDL-C $\bar{X}_{ \pm} \boldsymbol{S D}(\mathrm{mg} / \mathrm{dl})$ & $55 \pm 15$ & $\begin{array}{l}50 \pm 14 \\
p<0.01\end{array}$ & $56 \pm 15$ & $48 \pm 13$ & $\begin{array}{l}45 \pm 12 \\
p<0.01\end{array}$ & $49 \pm 13$ & $59 \pm 15$ & $\begin{array}{l}55 \pm 14 \\
p<0.01\end{array}$ & $59 \pm 15$ \\
\hline $\mathbf{L D L}-\mathbf{C} \overline{\boldsymbol{X}}_{ \pm} \boldsymbol{S D}(\mathrm{mg} / \mathrm{dl})$ & $129 \pm 41$ & $\begin{array}{l}114 \pm 41 \\
\mathrm{p}<0.01\end{array}$ & $131 \pm 40$ & $127 \pm 40$ & $\begin{array}{l}109 \pm 38 \\
p<0.01\end{array}$ & $132 \pm 39$ & $129 \pm 41$ & $\begin{array}{l}118 \pm 43 \\
p<0.01\end{array}$ & $131 \pm 40$ \\
\hline non-HDL-C $\bar{X}_{ \pm} \boldsymbol{S D}(\mathrm{mg} / \mathrm{dl})$ & $148 \pm 42$ & $\begin{array}{l}134 \pm 42 \\
p<0.01\end{array}$ & $150 \pm 42$ & $150 \pm 44$ & $\begin{array}{l}130 \pm 39 \\
p<0.01\end{array}$ & $154 \pm 43$ & $146 \pm 41$ & $\begin{array}{l}137 \pm 44 \\
p<0.01\end{array}$ & $147 \pm 41$ \\
\hline $\mathbf{T G} \bar{X}_{ \pm} \boldsymbol{S D}(\mathrm{mg} / \mathrm{dl})$ & $148 \pm 118$ & $\begin{array}{l}153 \pm 104 \\
p=0.03\end{array}$ & $147 \pm 121$ & $172 \pm 153$ & $\begin{array}{l}160 \pm 127 \\
p=0.01\end{array}$ & $174 \pm 158$ & $135 \pm 90$ & $\begin{array}{l}146 \pm 76 \\
p<0.01\end{array}$ & $133 \pm 92$ \\
\hline Treated for dyslipidaemia (n) & 4703 & 1296 & 3407 & 1899 & 651 & 1248 & 2804 & 645 & 2159 \\
\hline $\mathbf{T C} \bar{X}_{ \pm} \mathbf{S D}(\mathrm{mg} / \mathrm{dl})$ & $192 \pm 47$ & $\begin{array}{l}178 \pm 45 \\
p<0.01\end{array}$ & $197 \pm 46$ & $186 \pm 46$ & $\begin{array}{l}171 \pm 40 \\
p<0.01\end{array}$ & $194 \pm 47$ & $196 \pm 47$ & $\begin{array}{l}185 \pm 48 \\
p<0.01\end{array}$ & $199 \pm 46$ \\
\hline HDL-C $\bar{X}_{ \pm} \boldsymbol{S D}(\mathrm{mg} / \mathrm{dl})$ & $52 \pm 15$ & $\begin{array}{l}49 \pm 14 \\
p<0.01\end{array}$ & $54 \pm 15$ & $47 \pm 13$ & $\begin{array}{l}44 \pm 12 \\
p<0.01\end{array}$ & $48 \pm 14$ & $56 \pm 15$ & $\begin{array}{l}54 \pm 14 \\
p<0.01\end{array}$ & $57 \pm 15$ \\
\hline $\mathbf{L D L}-\mathbf{C} \overline{\boldsymbol{X}}_{ \pm} \boldsymbol{S D}(\mathrm{mg} / \mathrm{dl})$ & $118 \pm 42$ & $\begin{array}{l}108 \pm 40 \\
p<0.01\end{array}$ & $121 \pm 42$ & $115 \pm 39$ & $\begin{array}{l}105 \pm 36 \\
p<0.01\end{array}$ & $120 \pm 40$ & $120 \pm 44$ & $\begin{array}{l}110 \pm 43 \\
p<0.01\end{array}$ & $122 \pm 43$ \\
\hline non-HDL-C $\bar{X}_{ \pm} \boldsymbol{S D}(\mathrm{mg} / \mathrm{dl})$ & $139 \pm 44$ & $\begin{array}{l}129 \pm 42 \\
p<0.01\end{array}$ & $143 \pm 45$ & $139 \pm 45$ & $\begin{array}{l}127 \pm 38 \\
\mathrm{p}<0.01\end{array}$ & $146 \pm 47$ & $140 \pm 44$ & $\begin{array}{l}131 \pm 45 \\
p<0.01\end{array}$ & $142 \pm 44$ \\
\hline $\mathbf{T G} \bar{X}_{ \pm} \mathbf{S D}(\mathrm{mg} / \mathrm{dl})$ & $164 \pm 142$ & $\begin{array}{l}158 \pm 115 \\
p=0.03\end{array}$ & $167 \pm 150$ & $183 \pm 174$ & $\begin{array}{l}166 \pm 140 \\
p<0.01\end{array}$ & $192 \pm 189$ & $151 \pm 112$ & $\begin{array}{l}150 \pm 81 \\
p=0.57\end{array}$ & $152 \pm 120$ \\
\hline Non-treated for dyslipidaemia (n) & 9021 & 669 & 8352 & 3135 & 305 & 2830 & 5886 & 364 & 5522 \\
\hline $\mathbf{T C} \bar{X}_{ \pm} \mathbf{S D}(\mathrm{mg} / \mathrm{dl})$ & $208 \pm 42$ & $\begin{array}{l}195 \pm 44 \\
\mathrm{p}<0.01\end{array}$ & $209 \pm 42$ & $205 \pm 43$ & $\begin{array}{l}183 \pm 43 \\
p<0.01\end{array}$ & $207 \pm 42$ & $210 \pm 41$ & $\begin{array}{l}205 \pm 42 \\
p=0.02\end{array}$ & $210 \pm 41$ \\
\hline HDL-C $\bar{X}_{ \pm} \mathbf{S D}(\mathrm{mg} / \mathrm{dl})$ & $56 \pm 15$ & $\begin{array}{l}52 \pm 13 \\
p<0.01\end{array}$ & $57 \pm 15$ & $49 \pm 13$ & $\begin{array}{l}46 \pm 11 \\
p<0.01\end{array}$ & $49 \pm 13$ & $60 \pm 15$ & $\begin{array}{l}57 \pm 13 \\
p<0.01\end{array}$ & $60 \pm 15$ \\
\hline LDL-C $\bar{X}_{ \pm} \boldsymbol{S D}(\mathrm{mg} / \mathrm{dl})$ & $134 \pm 39$ & $\begin{array}{l}125 \pm 40 \\
p<0.01\end{array}$ & $135 \pm 38$ & $135 \pm 38$ & $\begin{array}{l}119 \pm 40 \\
p<0.01\end{array}$ & $137 \pm 38$ & $134 \pm 39$ & $\begin{array}{l}131 \pm 39 \\
p=0.11\end{array}$ & $134 \pm 39$ \\
\hline non-HDL-C $\overline{\boldsymbol{X}}_{ \pm} \boldsymbol{S D}(\mathrm{mg} / \mathrm{dl})$ & $152 \pm 40$ & $\begin{array}{l}144 \pm 40 \\
p<0.01\end{array}$ & $152 \pm 40$ & $156 \pm 42$ & $\begin{array}{l}138 \pm 40 \\
p<0.01\end{array}$ & $158 \pm 41$ & $150 \pm 40$ & $\begin{array}{l}148 \pm 40 \\
p=0.56\end{array}$ & $150 \pm 40$ \\
\hline $\mathbf{T G} \bar{X}_{ \pm} \mathbf{S D}(\mathrm{mg} / \mathrm{dl})$ & $140 \pm 103$ & $\begin{array}{l}144 \pm 80 \\
p=0.14\end{array}$ & $140 \pm 105$ & $165 \pm 137$ & $\begin{array}{l}151 \pm 92 \\
\mathrm{p}=0.01\end{array}$ & $166 \pm 141$ & $127 \pm 77$ & $\begin{array}{l}139 \pm 68 \\
p<0.01\end{array}$ & $126 \pm 77$ \\
\hline
\end{tabular}

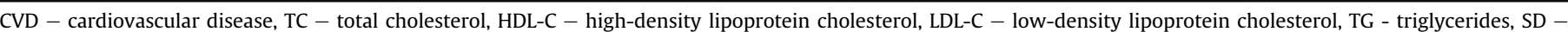
standard deviation.

To receive values in mmol/l: (1) for TC, HDL-C, and LDL-C please divide the value in $\mathrm{mg} / \mathrm{dl}$ by 38.67 ; (2) for TG please divide the value in mg/dl by 88.57 .

obesity was found in $54.5 \%$, respectively (Fig. 1b).

$17.4 \%$ patients without CVD were current smokers and $27.7 \%$ had smoked in the past. Among patients with diagnosed CVD, $13.0 \%$ were current smokers and 39.1\% had smoked in the past (Fig. 1c).

The number of CV risk factors was higher in both female and male patients with CVD in comparison with those without it $(\mathrm{p}<0.01)$. All participating in the study women had a significantly lower number of CV risk factors than men ( $<<0.01$ ) (Fig. 2a). The proportion of patients with multiple risk factors increased substantially with age - the correlation coefficient Gamma is 0.31 for the entire study population ( 0.39 for women, 0.20 for men). However, this phenomenon did not apply to the oldest age groups (Fig. 2b).Fig. 2.

\section{Discussion}

\subsection{Main findings}

In the population of men and women seeking medical care in primary health care practices in Poland in 2015 and 2016, nearly $19 \%$ of men and approximately $12 \%$ of women had CVD. Over $60 \%$ of the recruited patients had HTN, > 80\% had dyslipidaemia and $<15 \%$ of patients were previously diagnosed with DM. All of these disorders were more frequent in men. Overweight and obesity were present in more than three-quarters of patients with four-fifths of them exceeding the waist circumference norm for the European population. Slightly less than half of the patients were current smokers or had smoked in the past. Patients with CVD had significantly higher BP and glucose levels but lower LDL-C level. In patients with CVD, HTN and dyslipidaemia were twice as frequent and DM three times more so than in patients without it.

\subsection{Comparison with other studies}

There are substantial differences in the prevalence of CVD and $\mathrm{CV}$ risk factors between European countries. This fact is confirmed by recent studies on the prevalence of metabolic risk factors [20], HTN [21,22] and obesity [23]. A higher CVD mortality burden is found in CEE countries compared to that in Northern, Southern and Western European countries [24].

In NATPOL2011, which was conducted in Poland in 2011 on a representative sample of 2417 individuals from the general population aged from 18 to 79 years, HTN was found in $36.8 \%$ of men and $29.4 \%$ of women. Hypercholesterolaemia was present in $61.1 \%$ participants, DM occurred in $7.0 \%$ of men and $6.4 \%$ of women and obesity $-23.6 \%$ and $19.7 \%$, respectively [25].

In another study conducted in Poland in 2013-2014, WOBASZ II, hypertension occurred in $46.2 \%$ of men and $40.4 \%$ of women [26] and hypercholesterolaemia was found in $70.3 \%$ of men and in $64.3 \%$ of women [27]. Prevalence of obesity was $24.4 \%$ in men and $25.0 \%$ in women and the prevalence of overweight was $43.2 \%$ and $30.5 \%$, respectively. Excess waist circumference $(\geq 94 \mathrm{~cm}$ in men or 

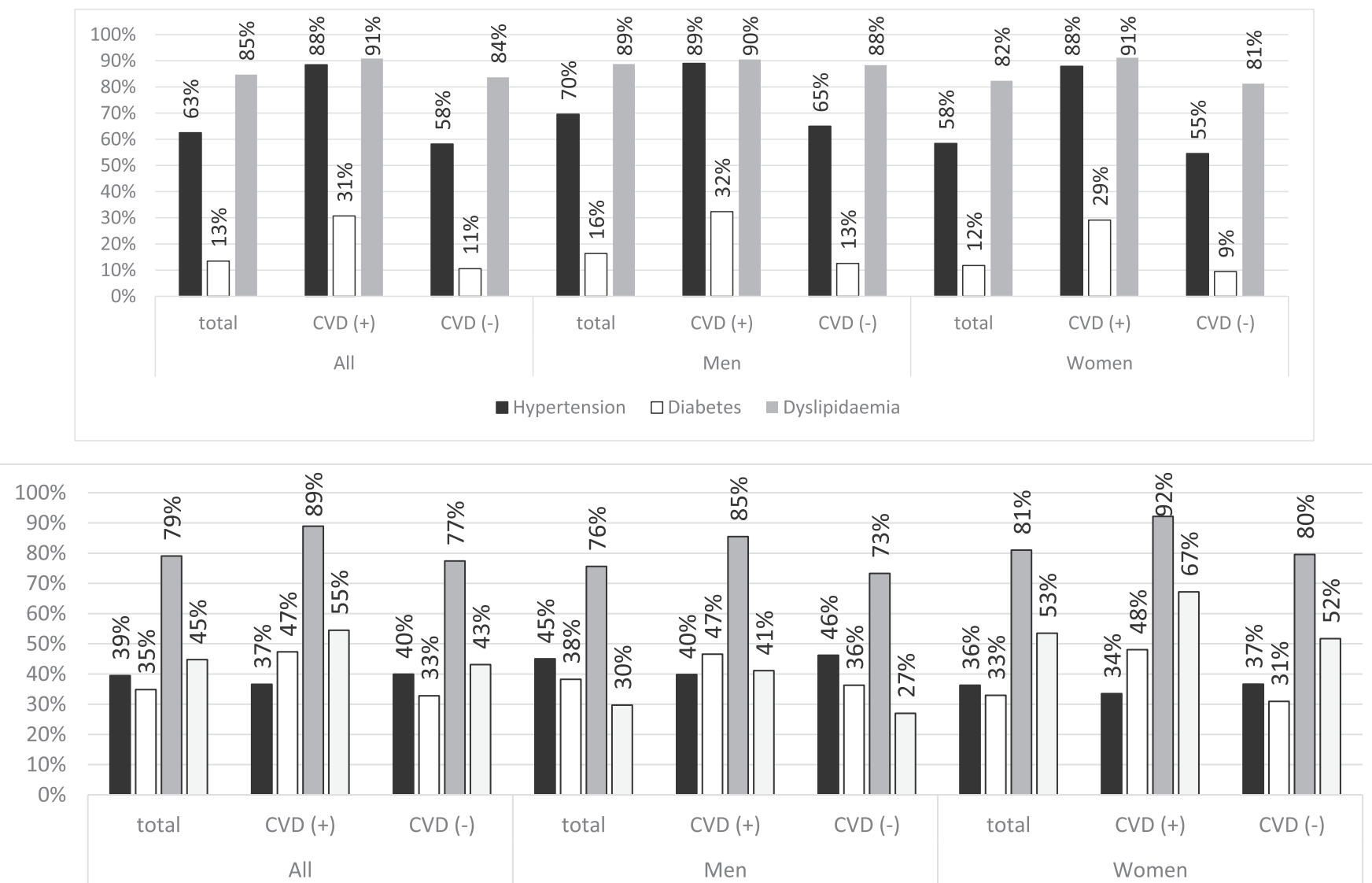

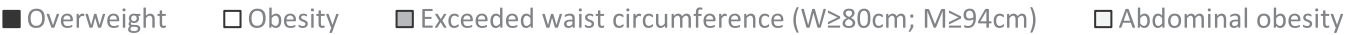

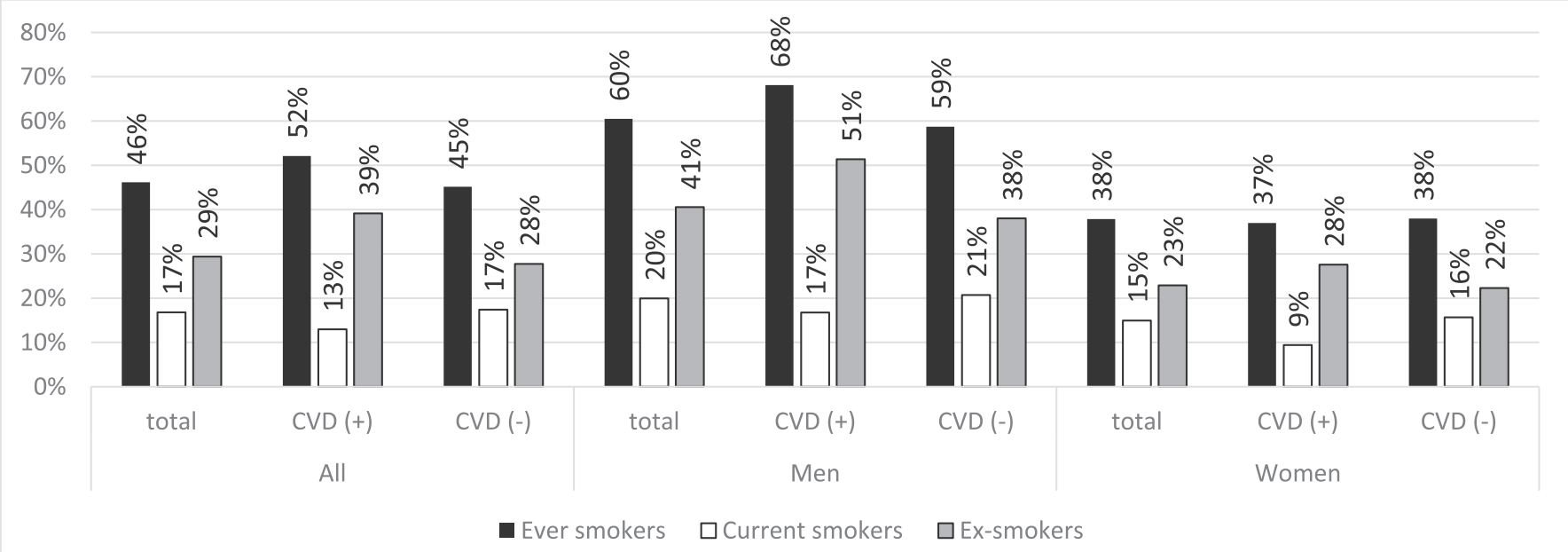

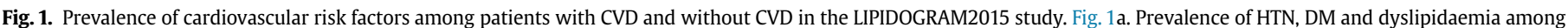

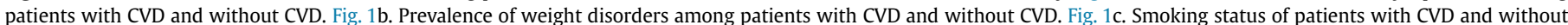
CVD. CVD - cardiovascular disease.

$\geq 80 \mathrm{~cm}$ in women) occurred in $59.4 \%$ of men and $67.4 \%$ of women [28]. The prevalence of regular tobacco smoking was $29.9 \%$ among men and 20.5\% among women [29]. However, the population in WOBASZ II study was older (above 20 years old). The participation rates for WOBASZ and WOBASZ II was around 75\% and 47\%, respectively. Some results were based on a survey questionnaire only and DM prevalence was not taken into consideration.
In the LIPIDOGRAM2004 and LIPIDOGRAM2006 studies, the prevalence rate of overweight and obesity among adult patients remaining under the care of family physicians in Poland were assessed. Approximately $75 \%$ of the patients included in studies had BMI $>25 \mathrm{~kg} / \mathrm{m}^{2}$. The overweight rate was higher among men than women (48.0\% vs $39.2 \%$ in 2004 , and $47.4 \%$ vs $39.7 \%$ in 2006). Obesity was present in $>30 \%$ of participants - in $200432.8 \%$ in men 

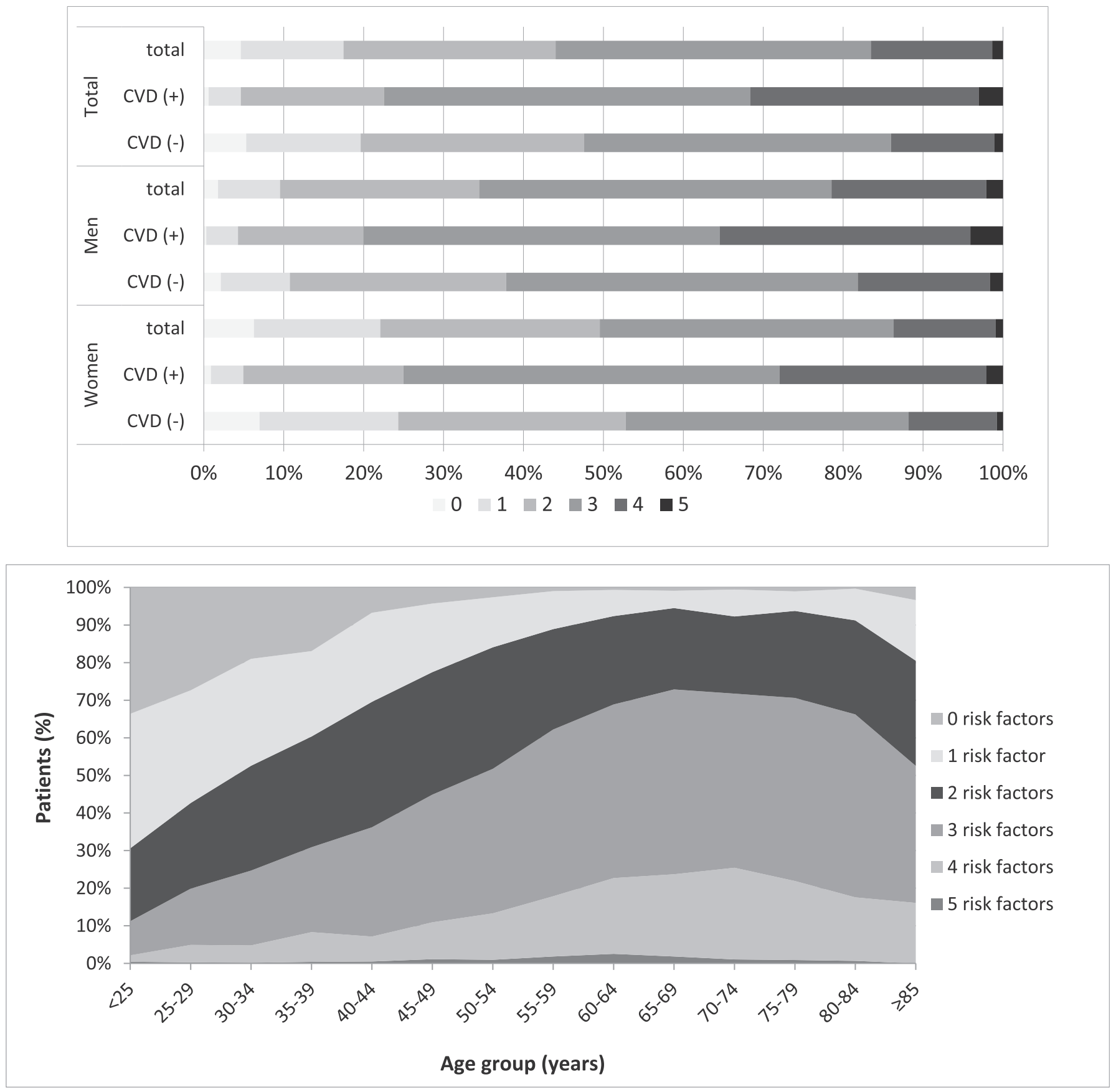

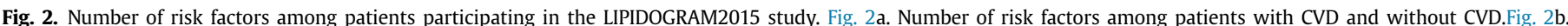

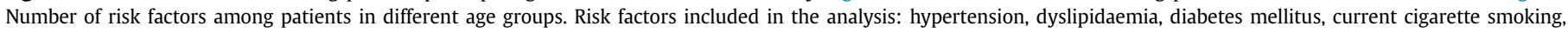
obesity (BMI $\geq 25$ ). CVD - cardiovascular disease.

and $31.2 \%$ in women and in $2006,34.7 \%$ and $31.6 \%$, respectively. In LIPIDOGRAM 2015, the obesity rate was even higher (38.2\% in men and $32.9 \%$ in women) $[7,30,31]$.

The results of the LIPIDOGRAM2015 study are similar to other studies from Central and Eastern Europe. In a project carried out in 2014-2016 on 1051 patients from the general population in Prague, Czech Republic, the prevalence of hypercholesterolaemia and hyperglycaemia were $49 \%$ and $12.8 \%$ in women and $52.9 \%$ and $18.9 \%$ in men, respectively. Obesity and overweight were present in $16.3 \%$ and $26.7 \%$ of women and $20.3 \%$ and $48.8 \%$ of men. Excess waist circumference was diagnosed in $56.1 \%$ of women and $57 \%$ of men.
However, the population in this study was limited to one city only and other CV risk factors, including HTN, were not taken into consideration [32]. In research conducted in 2007 on 1111 patients age 20-65 years from the general population in Tallinn, Estonia, HTN occurred in $26.1 \%$ of women and $36.8 \%$ of men. The prevalence of overweight and excess waist circumference was $48.3 \%$ and $44.5 \%$ in women and $62.6 \%$ and $48.5 \%$ in men, respectively. Hypercholesterolaemia and type $2 \mathrm{DM}$ were present in $62 \%$ and $2.7 \%$ of women and $70.7 \%$ and $4 \%$ of men. In $2007,20.5 \%$ of women and $36.1 \%$ of men were current smokers. However, the population in this study was also limited to one city only and other CV risk factors 
were not taken into consideration [33]. The higher prevalence of CV risk factors that was shown in our study may be caused by the composition of the study population as these were patients who sought medical assistance in primary health care practices and were not from the general population.

\subsection{Strengths and limitations}

To the best of our knowledge, this is the largest epidemiological study concerning CVD and CV risk factors representative of the regional distribution of residents in Poland in the last 5 years. This is the only study in Poland specifically aimed at the primary care patient population who seek medical care. Data uncovering the burden of CVD risk factors in a primary healthcare setting in Poland which may be of importance for other regions. Moreover, it is a hands-on study in which data has been collected in detail and is relevant for primary and secondary prevention. Other strengths of our study were that laboratory tests of lipids levels were carried out in the central laboratory and the fact that all physicianinvestigators underwent training.

There are also some obvious limitations. The study enrolled patients who seek medical assistance in primary health care practices and is not representative of the general Polish population since around $10 \%$ of patients in Poland are not entitled (due to lack of insurance or not choosing their GP) to use this service. The study period did not include the summer months, which may influence the results. A relatively large proportion of primary care physicians refused to participate in the study. Moreover, patients in individual practices were not recruited by a randomization process. Physicians enrolled patients consecutively. No follow-up was performed, which is one of the limitations often found in observational studies. Additionally, the glucose level was measured by a glucometer, not by the most precise method, hence these measurements were not taken into account for defining of glucose impairment.

\subsection{Interpretation and implication}

The study provides relevant, current and precise data on the prevalence of CVD and CV risk factors in a representative sample of patients attending primary healthcare for various reasons in Poland.

The results of the study draw attention to the fact that in Poland men less often than women use primary health care (1:3). The larger female population enrolled in the study is due to the fact that women report to primary care more often than men. A similar trend was observed in previous LIPIDOGRAM studies [7,8,30,31]. Because of that, it is also worth considering using female partners as a channel to reach men who do not use preventive and screening tests in primary healthcare.

The results of our study are important for family doctors. They confirm the well-known fact that CVD and CV risk factors occur frequently in the population covered by family doctor care, and also provide quantitative data in this field. Physicians should aware of the essential findings of this study. Firstly, CVD and its major risk factors are more common in men than women. Secondly, risk factors are more common in patients with CVD than without them. Both of these facts should be taken into account when planning activities in primary and secondary prevention. The results of our study can also be helpful for family doctors in the planning of continuous education and should be taken into account in the activities for the development of practices and quality improvement.

The results are also important for cardiologists. They indicate the possibility of taking action in primary health care in the field of primary and secondary CVD prevention and the need for close cooperation between cardiologists and family doctors in the diagnosis and treatment of patients with CVD.

Study results provide public health specialists with accurate data on the prevalence of risk factors and CVD. This data should be taken into account when planning policies, allocating resources and financing CVD prevention. This is particularly important, because in 2016 preventable mortality in Poland was 218 per 100,000 population and was significantly higher than the EU average of 161. Moreover, the central national audit carried out in Poland in the years 2012-2015 showed that the financing of preventive measures was insufficient and in addition, the funds were inappropriately allocated [11].

Researchers are able to make comparisons with previous LIPIDOGRAM studies and follow trends in the prevalence of CVD and $\mathrm{CV}$ risk factors in the population of patients attending primary healthcare in Poland. It also seems beneficial to continue research on primary healthcare patients in Poland in the future and to start similar research in the other countries of Central and Eastern Europe.

\section{Conclusions}

The prevalence of CVD and CV risk factors among patients attending primary healthcare in Poland is high, but it seems not to differ from the frequency in other countries of Central and Eastern Europe. The most common CV risk factors are excess waist circumference, dyslipidaemia and HTN. Among patients in the primary care setting seeking medical care in Poland, CVD is more common in men than in women. Family physicians working in primary health care, as well as health authorities at all levels from local to national, should conduct activities to prevent, diagnose early and treat CVD in the primary health care population.

\section{Authors}

JJJ and MB collected the data. JJJ, KS, TT, AW and MB analysed the data and edited the first draft and final versions of the manuscript. MM, ALC, RKK, DPM, TPP, HG, LGYH, MT, CFJ, SN, WB, MTM, DN, ŁS, SK developed models, reviewed results, provided guidance on methodology, or reviewed the manuscript, and approved the final version of the manuscript. JJJ, TT and MB - the first, corresponding and senior authors had full access to all the data in the study and had final responsibility for the decision to submit for publication.

\section{CRediT authorship contribution statement}

Jacek J. Jóźwiak: Conceptualization, Methodology, Data curation, Resources, Supervision, Writing - review \& editing. Krzysztof Studziński: Formal analysis, Writing - original draft, Visualization. Tomasz Tomasik: Formal analysis, Writing - original draft, Visualization, Supervision. Adam Windak: Writing - review \& editing. Mirosław Mastej: Writing - review \& editing. Alberico L. Catapano: Writing - review \& editing. Kausik K. Ray: Writing - review \& editing. Dimitri P. Mikhailidis: Writing - review \& editing. Peter P. Toth: Writing - review \& editing. George Howard: Writing review \& editing. Gregory Y.H. Lip: Writing - review \& editing. Maciej Tomaszewski: Writing - review \& editing. Fadi J. Charchar: Writing - review \& editing. Naveed Sattar: Writing - review \& editing. Bryan Williams: Writing - review \& editing. Thomas M. MacDonald: Writing - review \& editing. Dariusz Nowak: Writing review \& editing, Writing - review \& editing. Lukasz Skowron: Writing - review \& editing. Sławomir Kasperczyk: Writing - review \& editing. Maciej Banach: Conceptualization, Methodology, Data curation, Resources, Supervision, Writing - review \& editing. 


\section{Declaration of competing interest}

JJJ has received research grant/support from Valeant, and has served as a consultant or speaker for Valeant, Amgen, Teva, Servier, Boehringer Ingelheim, Celgene, Bioton, Microlife and ALAB Laboratories. TT has served as a consultant or speaker for Boehringer Ingelheim, Novartis, Shire, Biofarm, Eli Lilly. AW has served as a consultant or speaker for Merck, Boehringer Ingelheim, Sanofi Aventis, Bausch Health. ALC reports grants from Amgen, Sanofi, Regeneron personal fees from Merck, Sanofi, Regeneron, AstraZeneca, Amgen, Novartis, outside the submitted work. DPM has given talks and attended conferences sponsored by Amgen, Novonordisk and Libytec. MTM has no direct competing interests in regards to this paper. His dept holds or has held research grants from Pfizer, Amgen, Ipsen, Shire, Teijin \& Menarini. He was or has been the principal investigator on trials paid for by: Pfizer, Novartis, Ipsen, Teijin \& Menarini. In the last 5 years have been paid consulting or speakers fees by Novartis, Takeda, Shire, \& AstraZeneca. ŁS has given talks and attended conferences sponsored by Janssen-Cilag, Pfizer, Krka. SK has served as a speaker for Novartis. MB has received research grant(s)/support from Amgen, Mylan, Sanofi and Valeant, and has served as a consultant for Amgen, Daiichi-Sankyo, Esperion, Freia Pharmaceuticals, Herbapol, Kogen, KRKA, Mylan, Novartis, Novo-Nordisk, Polfarmex, Polpharma, Sanofi-Aventis, Servier, and Zentiva.

\section{Acknowledgements}

The present study was an initiative of the Polish Lipid Association (PoLA) and the College of Family Physician in Poland (CFPiP). The present study was funded by an unrestricted educational grant from Valeant. As a supporter of the study, Valeant had no role in study design, data analysis, data interpretation, or writing of the report. The present study was also supported by Silesian Analytical Laboratories (SLA), CHDE, BIO-RAD. The work of ALC has been supported by Ministry of Health - Ricerca Corrente - IRCCS MultiMedica, PRIN 2017H5F943 and ERANET ER-2017-2364981. In addition, we would like to thank all volunteer investigators, all volunteer staff and all participants. The list of the LIPIDOGRAM 2015 investigators is presented in Supplementary material 3. This article is part of a Supplement entitled "Plasma lipids and cardiovascular risk: Nutritional and therapeutic approaches" published with support from Società Italiana di Terapia Clinica e Sperimentale (SITeCS).

\section{Appendix A. Supplementary data}

Supplementary data to this article can be found online at https://doi.org/10.1016/j.atherosclerosissup.2021.01.004.

\section{References}

[1] WHO Mortality Database. http://apps.who.int/healthinfo/statistics/mortality/ whodpms/.

[2] Roth GA, Mensah GA, Johnson CO, et al., GBD-NHLBI-JACC Global Burden of Cardiovascular Diseases Writing Group. Global Burden of Cardiovascular Diseases and Risk Factors, 1990-2019: Update From the GBD 2019 Study. J Am $\begin{array}{llll}\text { Coll Cardiol 2020;76(25):2982-3021. https://doi.org/10.1016/ } & \text {. }\end{array}$ j.jacc.2020.11.010.

[3] GBD 2017 Causes of Death Collaborators. Global, regional, and national agesex-specific mortality for 282 causes of death in 195 countries and territories, 1980-2017: a systematic analysis for the Global Burden of Disease Study 2017. Lancet (London, England) 2018;392:1736-88. https://doi.org/ 10.1016/S0140-6736(18)32203-7.

[4] Zdrojewski T, Rutkowski M, Bandosz P, et al. Rozpowszechnienie i kontrola czynników ryzyka sercowo-naczyniowego w Polsce. Cele i sposób realizacji badania NATPOL 2011. Kardiol Pol 2013;71:381-92. https://doi.org/10.5603/ KP.2013.0066.

[5] Banach M, Jankowski P, Jóźwiak J, et al. PoLA/CFPiP/PCS guidelines for the management of dyslipidaemias for family physicians 2016. Arch Med Sci 2017;13:1-45. https://doi.org/10.5114/aoms.2017.64712.

[6] Drygas W, Niklas AA, Piwońska A, et al. Wieloośrodkowe ogólnopolskie Badanie stanu Zdrowia Ludności (badanie WOBASZ II): założenia, metody i realizacja. Kardiol Pol 2016;74:681-90. https://doi.org/10.5603/ KP.a2015.0235.

[7] Tomasik T, Jozwiak J, Windak A, et al. Prevention of coronary heart disease in primary medical care in Poland: results from the LIPIDOGRAM study. Eur J Cardiovasc Prev Rehabil 2011;18:287-96. https://doi.org/10.1177/ 1741826710389366.

[8] Kaess BM, Jozwiak J, Mastej M, et al. Association between anthropometric obesity measures and coronary artery disease: a cross-sectional survey of 16,657 subjects from 444 Polish cities. Heart 2010;96:131-5. https://doi.org/ 10.1136/hrt.2009.171520.

[9] Piepoli MF, Hoes AW, Agewall S, et al. European Guidelines on cardiovascular disease prevention in clinical practice. Eur Heart J 2016;37:2315-81. https:// doi.org/10.1093/eurheartj/ehw106. 2016

[10] Soran H, Adam S, Mohammad JB, et al. Hypercholesterolaemia - practical information for non-specialists. Arch Med Sci 2018;14:1-21. https://doi.org/ 10.5114/aoms.2018.72238.

[11] OECD/European Observatory on Health Systems and Policies. Poland: country health profile 2019, state of health in the EU, vols. 1-23. OECD Publ; 2019. 2019, https://ec.europa.eu/health/sites/health/files/state/docs/2019_chp_be_ english.pdf.

[12] Jóźwiak JJ, Kasperczyk S, Tomasik T, et al. Design and rationale of a nationwide screening analysis from the LIPIDOGRAM2015 and LIPIDOGEN2015 study. 2020. https://doi.org/10.5114/aoms.2020.96052.

[13] Reiner Z, Catapano AL, De Backer G, et al. ESC/EAS guidelines for the management of dyslipidaemias: the task force for the management of dyslipidaemias of the European society of Cardiology (ESC) and the European atherosclerosis society (EAS). Eur Heart J 2011;32:1769-818. https://doi.org/ 10.1093/eurheartj/ehr158.

[14] Kermani SK, Khatony A, Jalali R, et al. Accuracy and precision of measured blood sugar values by three glucometers compared to the standard technique. J Clin Diagn Res 2017;11. https://doi.org/10.7860/JCDR/2017/23926.9613. OC05-8.

[15] Mancia G, Fagard R, Narkiewicz K, et al. ESH/ESC guidelines for the management of arterial hypertension: the task force for the management of arterial hypertension of the European society of hypertension (ESH) and of the European society of Cardiology (ESC). Eur Heart J 2013;34:2159-219. https:// doi.org/10.1093/eurheartj/eht151. 2013.

[16] Tykarski A, Narkiewicz K, Gaciong Z, et al. Guidelines for the management of hypertension. Recommendations of the Polish Society of Hypertension short version. Kardiol Pol 2015;73:676-700. https://doi.org/10.5603/ KP.2015.0157. 2015.

[17] Młynarski W, Cypryk K, Hiszpania C, et al. Guidelines on the management of diabetic patients. A position of Diabetes Poland. 2015. 2015.

[18] WHO. Body mass index (BMI) classifications. http://apps.who.int/bmi/index. jsp?introPage=intro_3.html. [Accessed 22 December 2019].

[19] Alberti KGMM, Zimmet P, Shaw J. Metabolic syndrome-a new world-wide definition. A consensus statement from the international diabetes federation. Diabet Med 2006;23:469-80. https://doi.org/10.1111/j.14645491.2006.01858.x.

[20] GBD 2017 Risk Factor Collaborators. Global, regional, and national comparative risk assessment of 84 behavioural, environmental and occupational, and metabolic risks or clusters of risks for 195 countries and territories, 19902017: a systematic analysis for the Global Burden of Disease Stu. Lancet (London, England) 2018;392:1923-94. https://doi.org/10.1016/S01406736(18)32225-6.

[21] NCD Risk Factor Collaboration (NCD-RisC). Contributions of mean and shape of blood pressure distribution to worldwide trends and variations in raised blood pressure: a pooled analysis of 1018 population-based measurement studies with 88.6 million participants. Int J Epidemiol 2018. https://doi.org/ 10.1093/ije/dyy016. Published Online First: 19 March.

[22] Beaney T, Schutte AE, Tomaszewski M, et al. May Measurement Month 2017: an analysis of blood pressure screening results worldwide. Lancet Glob Health 2018;6:e736-43. https://doi.org/10.1016/S2214-109X(18)30259-6.

[23] NCD Risk Factor Collaboration (NCD-RisC). Worldwide trends in body-mass index, underweight, overweight, and obesity from 1975 to 2016: a pooled analysis of 2416 population-based measurement studies in 128.9 million children, adolescents, and adults. Lancet (London, England) 2017;390: 2627-42. https://doi.org/10.1016/S0140-6736(17)32129-3.

[24] GBD 2017 Mortality Collaborators. Global, regional, and national age-sexspecific mortality and life expectancy, 1950-2017: a systematic analysis for the Global Burden of Disease Study 2017. Lancet (London, England) 2018;392: 1684-735. https://doi.org/10.1016/S0140-6736(18)31891-9.

[25] Zdrojewski T, Rutkowski M, Bandosz P, et al. [Assessment of the prevalence and control of cardiovascular risk factors in Poland - NATPOL 1997, 2002, 2011 studies]. In: [Epidemiology and prevention of cardiovascular diseases]. Kraków: Medycyna Praktyczna; 2015. p. 57-64.

[26] Niklas A, Flotyńska A, Puch-Walczak A, et al. Prevalence, awareness, treatment and control of hypertension in the adult polish population - multi-center national population health examination surveys - WOBASZ studies. Arch Med Sci 2018;14:951-61. https://doi.org/10.5114/aoms.2017.72423.

[27] Pająk A, Szafraniec K, Polak M, et al. Changes in the prevalence, management 
and treatment of hypercholesterolemia and other dyslipidemias over 10 years in Poland. The WOBASZ study. Polish Arch Intern Med 2016. https://doi.org/ 10.20452/pamw.3464. Published Online First: 19 July.

[28] Stepaniak U, Micek A, Waśkiewicz A, et al. Prevalence of general and abdominal obesity and overweight among adults in Poland Results of the WOBASZ II study (2013-2014) and comparison with the WOBASZ study (2003-2005). Pol Arch Med Wewn 2016;126:662-71. https://doi.org/ 10.20452/pamw.3499.

[29] Polakowska M, Kaleta D, Piotrowski W, et al. Tobacco smoking in Poland in the years from 2003 to 2014 multi-centre national population health examination survey (WOBASZ). Pol Arch Intern Med 2017;127 127:91-9. https:// doi.org/10.20452/pamw.3896.

[30] Jóźwiak J, Lukas W, Rygiel K, et al. The prevalence rate of overweight and obesity among adult patient population in Poland, according to the LIPIDOGRAM2004 and LIPIDOGRAM2006 studies, in context of previous Polish national screening surveys. Przegl Lek 2011;68:316-9.

[31] Kaess BM, Jóźwiak J, Nelson CP, et al. The relation of rapid changes in obesity measures to lipid profile - insights from a nationwide metabolic health survey in 444 Polish cities. PLoS One 2014;9:e86837. https://doi.org/10.1371/ journal.pone.0086837.

[32] Pavlík V, Fajfrová J, Šafka V, et al. Prevalence of risk factors in cardiovascular diseases in selected population of the Czech Republic. Cent Eur J Publ Health 2018;26:118-23. https://doi.org/10.21101/cejph.a5192.

[33] Kaldmäe M, Zemtsovskaja G, Abina J, et al. Prevalence of cardiovascular disease risk factors in Tallinn, Estonia. Med 2017;53:268-76. https://doi.org 10.1016/j.medici.2017.07.002. 